\title{
O abalo das certezas pela pandemia de Covid-19
}

\author{
The shaking of certainties by the Covid-19 \\ pandemic
}

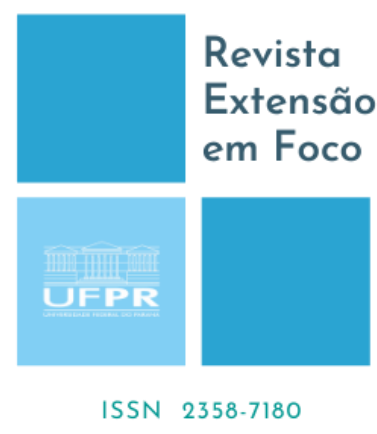

Márcia von Frühauf Firme ${ }^{1}$

RESUMO

Neste texto, apresentamos um relato de experiência a partir da escrita de cartas, proporcionado pelo projeto de extensão para formação de professores Cirandar: rodas de investigação na escola, promovido pela Universidade Federal do Rio Grande (FURG), na região de Bagé, no Rio Grande do Sul, durante o período de agosto de 2020 a abril de 2021. No relato, visamos mostrar alguns aspectos deste processo de autoformação, a partir de cartas recebidas por e-mail da coordenação do projeto, orientando a escrita das cartas dos participantes. Iniciando pela primeira carta, com a apresentação dos integrantes do grupo; a segunda carta, sobre os temas de interesse para estudo e discussões sobre os desafios da docência e da adaptação ao modo remoto de trabalhar; e na terceira carta, uma discussão teórica sobre aprendizagem ativa que finaliza com algumas considerações sobre as aprendizagens promovidas por esse processo formativo. Destaca-se, nessa edição do Cirandar, o acolhimento por meio da liberdade de escrita sobre os sentimentos nesse período, a reflexão provocada pelos questionamentos feitos pelos pares de leitura e o espaço para pensarmos sobre nós mesmos e a profissão docente.

Palavras-chave: Cirandar. Aprendizagem Ativa. Formação de Professores.

\section{ABSTRACT}

In this text, we present an experience report, using, as a starting point, the writing of letters, provided by the extension project for teacher education Cirandar: research circles at school, promoted by Universidade Federal do Rio Grande (FURG), in the region of Bagé in the State of Rio Grande do Sul, during the time period of August, 2020 to April, 2021. In the report, we aim to show some aspects of this process of selfformation, based on letters received on the e-mail of the project coordination, orienting the writing of letters by the participants. Starting by the first letter, with the presentation of the members of the group; the second letter, about the topics of interest to study and discussions on the challenges of teaching and the adaptation to the remote way of working; and in the third letter, a theoretical discussion about active learning that ends with some considerations about the learnings provided by this formative process. It is highlighted, in this edition of Cirandar, the welcoming through the freedom to write about the feelings in this period of time, the reflection induced by the questioning made by the reading peers and the space to think about ourselves and teaching.

Keywords: Cirandar. Active Learning. Teacher Education.

\footnotetext{
${ }^{1}$ Doutora em Educação em Ciências: Química da Vida e Saúde. Docente Adjunta na Universidade Federal do Pampa (UNIPAMPA), Bagé, RS, Brasil. E-mail: marciafirme@unipampa.edu.br. Orcid: https://orcid.org/0000-0002-5444-7284
} 


\section{INTRODUÇÃO}

Em um período de tantas incertezas provocadas pela pandemia causada pelo coronavírus SARS-CoV-2, poder dialogar com nossos pares, partilhando experiências angústias e aprenderes sobre a docência nos possibilita momentos de inspiração. Neste contexto, o processo formativo Cirandar: rodas de investigação na escola, iniciou em 2012 e a cada ano se reorganiza a partir das vozes de seus participantes. Desde 2015, ocorre também a distância, a partir da mediação por cartas acolhedoras e orientadoras deste processo formativo, enviadas pela coordenadora professora Maria do Carmo aos e-mails dos participantes e no período anterior a pandemia, finalizava com encontros presenciais.

Com o passar dos anos, muitos professores integrantes do nosso grupo de pesquisa CEAMECIM (Comunidades Aprendentes em Educação Ambiental, Ciências e Matemática, do Conselho Nacional de Pesquisa e Desenvolvimento Científico e Tecnológico $(\mathrm{CNPq})$ ) na FURG, orientados pela professora Maria do Carmo Galiazzi foram se distanciando, mas a vontade de seguir juntos era grande, e assim foram surgindo as redes de coordenadores, inicialmente tímidas. A partir deste ano, as cartas seguiram orientando a todos os inscritos, e ocorreram encontros de forma remota em cada um dos grupos com 20 coordenadores regionais e finalizando com um belíssimo encontro virtual com todos os participantes. Os encontros virtuais dos coordenadores ocorriam mensalmente para relatarmos o movimento de cada grupo e planejarmos como seriam as próximas etapas, em um movimento democrático de escuta e de tomada de decisões.

Neste contexto, coordeno a região de Bagé (RS), onde realizamos três encontros virtuais: o primeiro para nos conhecermos e contarmos nossa primeira carta, o segundo para conversarmos sobre como estávamos nos sentindo perante a pandemia de Covid-19 e o que pretendíamos investigar, e o terceiro, para conversar a respeito do envio do relato e de como seria a leitura em pares. Alguns desses momentos, assim como um estudo sobre aprendizagem ativa e sua relação com esse processo de formação de professores, serão mostrados por meio de três cartas durante o texto. Este finaliza com algumas considerações a respeito do que o Cirandar representou para os participantes deste grupo da região da campanha. 


\section{O ENCONTRO COM O CIRANDAR}

Primeira carta - Bagé, 21 de setembro de 2020

Prezados(as) Cirandeiros e Cirandeiras,

Nesta carta, descreverei como foi o encontro com o Cirandar dos nove participantes da Região de Bagé, destes, cinco são professoras, quatro da Educação Básica e duas do Ensino Superior, um licenciando participante do Programa de Residência Pedagógica e um pós-graduando do Mestrado em Ensino da Unipampa.

Uma das professoras trabalha em duas cidades próximas a Bagé, Lavras do Sul e Dom Pedrito, sendo nesta última em escola rural. Conheceu o Cirandar pelo convite de sua orientadora de Mestrado em Ensino de Ciências da UNIPAMPA, do campus de Caçapava do Sul. Outra conheceu pelas lives que aconteciam às segundas feiras à tarde durante o primeiro semestre de 2020. E três professoras receberam indicações e convite de amigas e colegas. O licenciando e o pós-graduando foram apresentados ao Cirandar por mim, durante a graduação. Todos com exceção minha e do pós-graduando, participam pela primeira vez desse processo formativo. E a partir disso também me apresento a vocês.

Sou professora do Ensino Superior, da Universidade Federal do Pampa (UNIPAMPA) desde 2013, anteriormente trabalhei na Educação Básica por 17 anos, desde que me formei na Licenciatura em Química. A partir do inicio da docência sentia que sempre parecia faltar algo, e ao voltar a participar de cursos, de grupos de estudos com licenciandos e professores em formação continuada, passei a sentir que fazia parte de algo, uma comunidade aprendente como Carlos Brandão (2005) falava, quando temos um repertório de interesses compartilhado. Infelizmente na escola é muito raro termos espaços para estudo e formação por nós mesmos.

Mas o ápice de como cheguei até o Cirandar, tem a ver com minha primeira participação no VII Encontro de Investigação na Escola (EIE), na PUCRS em 2007. Para participar desse encontro, por critério do evento, é necessário escrever um relato de experiência e este é submetido a leitura crítica de outro participante e posteriormente discutidos em grupos temáticos. O VII EIE foi a primeira vez que assumi a autoria de 
um trabalho, me senti com capacidade e muita satisfação por estar fazendo algo que fez com que me sentisse bem. A partir desse marco, com contribuição também das políticas públicas, fui retornando aos estudos, iniciando a pós-graduação, o que me permitiu participar de eventos como o EIE em diversas cidades do Rio Grande do Sul e também em Córdoba, na Argentina.

Em julho de 2011 participei do Encontro Ibero Americano de Investigação na Escola em Córdoba, e lá durante um café, em conversa com minha orientadora, Maria do Carmo e com a Aline, parceira de orientação, juntamente com o professor Daniel Suarez foi pensado o Cirandar. No caminho de volta, conversamos sobre a possibilidade de oferecer o Cirandar para professores em Rio Grande.

E como na educação tudo está em constante mudança, no ano de 2012, o Ensino Médio das escolas públicas do RS foi reestruturado e com isso surgiu uma nova componente curricular, o Seminário Integrado. Diante dessa reformulação, a dúvida dos professores passou a ser sobre como realizar o Seminário Integrado? A partir disso, o Cirandar, em sua primeira edição foi realizado com professores de Seminário Integrado, e nas edições seguintes mais professores foram se agregando a esse processo de formação acadêmico-profissional (DINIZ-PEREIRA, 2008), em que professores da escola e da universidade assim como licenciandos compartilham experiências e reflexões sobre a sala de aula e da docência.

Do ano de 2015 em diante, com a distância de muitos professores do nosso grupo por estarem trabalhando em diversas cidades, a professora Maria do Carmo, recordando-se da sensação agradável de escrever e receber cartas aliada à vontade de estarmos juntos, possibilitou nossa participação no Cirandar a distância por meio das orientações escritas nas cartas enviadas mensalmente por e-mail aos participantes. E assim seguimos até hoje e em permanente Cirandar.

Cada ano que passa, vamos conhecendo e agregando professores de diversas áreas e lugares. Como será nesse ano? Pergunta que também foi manifestada pela maioria dos participantes deste grupo.

Uma ótima semana a todos e todas! 


\section{DIANTE DE TANTAS INCERTEZAS, ESTUDAR O QUÊ?}

Segunda carta - Bagé, 25 de outubro de 2020

Prezados leitores, seguimos nesse distanciamento social devido à pandemia provocada pelo Coronavírus que causa a Covid-19. Já se passaram sete meses e ao pensar em todo esse tempo, percebi o quanto a angústia aumentava cada vez que vinha aquela sensação de preciso dar conta, mas afinal, dar conta do quê?

Ainda em março, com aquela esperança de que seria pouco tempo, não havíamos nem iniciado as aulas na universidade e elas já foram suspensas! Assim voltei para algumas leituras de férias, a cuidar das plantas ornamentais e da horta, a fazer atividades físicas acompanhadas de uma alimentação saudável, reduzindo o açúcar e a gordura. Mas também procurei informações em diversos sites sobre a situação, e aí, comecei a ficar preocupada, com medo de perder alguma pessoa querida devido a essa doença.

Nesse período, discuti com familiares por telefone, por ainda não acreditarem que o risco era real e sério, afinal de contas, tudo estava parando. Inclusive cancelaram Olimpíadas, Fórmula 1 e campeonatos de futebol, eventos esportivos que têm muitos investidores envolvidos. Estava ficando neurótica acompanhando todas as notícias. Só em ver pessoas já começava a tossir! Relatos que também foram partilhados pelos participantes do grupo. Possivelmente a segunda carta recebida nos permitiu a liberdade de escrever sobre nossos sentimentos nesse período.

Mas voltando para a sensação de preciso dar conta, afinal, dar conta do quê? Sou professora, e no meu caso, servidora pública, me cobrava para mostrar serviço, afinal de contas, como vamos receber sem trabalhar? Felizmente, fui convidada pelos meus amigos, colegas do curso de Licenciatura em Química para participar do projeto de extensão Etanóis, que destila bebidas alcóolicas apreendidas pela Receita Federal e transforma em álcool $70 \%$ a ser distribuído em diversos lugares incluindo comunidades indígenas e quilombolas. E aí também começaram os cursos, as lives, as proposições de projetos e os dias parecem que voar, e mais novas demandas surgiam, como reuniões, grupos de estudo e também a preocupação com os estudantes. 
Na segunda quinzena de abril até a primeira de junho, participei de um projeto de extensão com colegas da Matemática e da Química da UNIPAMPA sobre aprendizagens ativas. Neste, formamos um grupo de estudos, e posteriormente, organizamos um curso de formação de professores, desenvolvido em quatro encontros com professores de diversas cidades e áreas de formação. Foi exaustivo inicialmente, pois tivemos que conhecer e aprender a trabalhar de forma remota, no entanto, se tornou muito gratificante por ter nos proporcionado a oportunidade de aprendermos uns com os outros como ocorre aqui no Cirandar.

Lembrando-me disso, decidi que a aprendizagem ativa seria meu tema de estudo, até porque no ensino de modo remoto precisamos identificar formas, meios e recursos que possam contribuir com a aprendizagem de nossos estudantes. Os demais participantes do grupo também apresentaram seus temas de estudo durante a conversa no segundo encontro virtual. Estes temas também estavam relacionados com as experiências vivenciadas durante aquele período, os desafios do ensino remoto tanto para professores quanto para estudantes, o planejamento das aulas e os desafios tecnológicos, as questões sociais e ambientais relacionadas também ao aumento do consumo e produção de lixo e sobre a formação de professores para esses tempos de aulas à distância.

Enfim, chegou o inverno, o número de casos de Covid-19 e de mortes aqui no Brasil aumentaram muito, e o distanciamento social foi mantido. Como é difícil! Se tem algo que gosto muito é participar de uma roda de chimarrão, fazer um churrasco com os amigos e jogar Imagem e Ação. Mas além da necessidade de mantermos o distanciamento, os afazeres de trabalho aumentaram, e agora, precisamos dar conta dos prazos.

No início de setembro, retornamos as aulas de forma remota na UNIPAMPA, com dúvidas de como estas seriam, se haveriam estudantes matriculados e se conseguiriam acompanhar as aulas e atividades propostas? Tudo isso traz a tona a sensação de incerteza. Por falar nas incertezas, lendo sobre essa temática me deparei com as palavras "espere pelo inesperado", ditas por um senhor de 98 anos que admiro muito, Edgar Morin. Ainda seguindo na leitura desse autor, "o confinamento estimula as capacidades auto-organizadoras para remediar, por meio de leituras, músicas e filmes, a perda da liberdade de deslocamento. Desse modo, autonomia e inventividade são estimuladas pela crise" (MORIN, 2020, p.1). Entendi esse momento como uma 
oportunidade de fazer o diferente, de criar, e para isso poder conversar com nossos pares, no caso, com vocês professores. O que e como podemos fazer diferente para proporcionar uma educação de qualidade e valorizarmos nossa profissão docente?

Mesmo pensando em nossa profissão não podemos esquecer que somos pessoas, com famílias, com amigos e que também queremos qualidade de vida. De acordo com Morin,

Como a crise existencial, nos obriga a questionar nosso modo de vida, nossas verdadeiras necessidades, nossas verdadeiras aspirações encobertas pela alienação da vida cotidiana, a saber diferenciar o entretenimento pascaliano, que nos desvia de nossas verdades, da felicidade que encontramos na leitura de um livro, na escuta ou na contemplação das obras-primas que nos fazem encarar nosso destino humano" (MORIN, 2020, p.1).

Nesse aspecto, Edgar Morin com sua vasta experiência de vida, incluindo a Segunda Guerra Mundial, me fez lembrar de que não encontraremos certezas, mas talvez, um pouco de tranquilidade ao nos dar conta de que não existem verdades absolutas e que as incertezas sempre estarão no nosso caminho, mas talvez tenhamos a chance de escolhermos os melhores caminhos para nos tornarmos melhores seres humanos. E assim finalizo essa carta com muitas incertezas, mas com um sentimento fortalecido por esse grupo e pelo Cirandar.

Um ótimo final de domingo e até amanhã cirandeiros e cirandeiras!

Abraços da Márcia Firme

\section{APRENDER NA CONTEMPORANEIDADE}

\section{Terceira carta - Bagé, 27 de março de 2021}

\section{Prezados Cirandeiros e Cirandeiras,}

Após um ano de pandemia escrevo para contar alguns acontecimentos e reflexões ocorridas durante este período, dialogando com o eu profissional e muitas vezes imbricado com o pessoal, afinal, somos inteiros e não um ou outro. 
Na segunda quinzena de abril até a metade do mês de junho, participei do grupo de estudos sobre aprenderes na contemporaneidade, com colegas da Matemática e da Química e alguns mestrandos(as). Nesse estudamos Aprendizagem Crítica, Aprendizagem Colaborativa, Aprendizagem Solidária e Aprendizagem Ativa. Naquele período, voltei a sentir que fazia parte de algo, uma comunidade aprendente, como no tempo em que iniciei como professora da Educação Básica.

Nesse grupo de estudo, cada aprendizagem foi apresentada por um dos integrantes do grupo e discutida concomitantemente, possibilitando reflexões e aprofundamento teórico a partir de diversos autores. Na sequência elaboramos uma ação de extensão por meio de um curso sobre aprenderes na contemporaneidade, em quatro encontros síncronos, para professores de diversas cidades e áreas de formação. Os textos e as apresentações que fundamentaram as discussões foram disponibilizados por e-mail ou no grupo de Whatsapp (Grupo Aprenderes), ambiente criado para garantir maior efetividade na divulgação encaminhamento de dúvidas e sugestões.

Durante o curso, as reflexões teóricas foram exemplificadas em vivências das práticas docentes das formadoras e dos participantes, que interagiram de forma significativa em todos os encontros, lembrando a horizontalidade que ocorre no Cirandar. Por falar em Cirandar, desde março e sempre que estava sem reuniões, assisti às lives nas segundas feiras e eis que em julho fomos convidados a co-coordenar este projeto em nossas cidades. Desde então estamos envolvidos nesse processo formativo e pensando no tema a ser estudado e na escrita dessa carta. A aprendizagem ativa apresentada por mim no referido curso, também tornou-se foco do tema de estudo para o Cirandar.

Para inicio de conversa, a aprendizagem segundo Ivan Izquierdo é o processo através do qual nós adquirimos conhecimento sobre o mundo, e está relacionada com a memória, ou seja, com a aquisição, formação, conservação e evocação de informações, pois “só se grava o que foi aprendido da memória" (IZQUIERDO, 2011, p.11).

Considerando a relação entre aprendizagem e memória, é interessante compreender como ocorre a formação das memórias. Para Melanie Zwicker (2017), a formação das memórias inicia com a fase da aquisição, por meio da chegada da informação pelos estímulos aos sistemas sensoriais da visão, audição, tato, olfato, paladar e cinestesia. Esta última, ligada à posição do corpo no espaço e aos 
movimentos. E a partir da confrontação, da significação e da reincidência dos fatos é que ocorre a gravação de algo na memória.

Desta forma, para que haja apropriação do conhecimento, a novidade e o contraste são fatores que despertam a atenção, e estes somados a conexão com memórias consolidadas e a emoção são fatores extremamente importantes para a fixação de um conteúdo na memória e, consequentemente, para a aprendizagem (ZWICKER, 2017). A partir dessas considerações, como podemos contribuir para que a aprendizagem aconteça?

$\mathrm{O}$ artigo intitulado Abandono da narrativa, ensino centrado no aluno e aprender a aprender criticamente do Marco Antônio Moreira (2011), é uma ótima leitura! Nos provoca a partir da metáfora citada por Finkel (2008 apud Moreira, 2011 p.4) "dar aula com a boca fechada" a qual é usada para problematizar as suposições clássicas sobre a boa docência, que para esse autor, é aquela que cria circunstâncias que conduzem à aprendizagem relevante, duradoura. E na educação, a prioridade deveria ser da aprendizagem e não do ensino. Nesta perspectiva, "aprender é o objetivo e ensinar é um meio para este fim" (FINKEL, 2008 apud MOREIRA, 2011 p.4). Essas frases parecem indicar a necessidade de se pensar em uma aprendizagem mais significativa, progressiva, em que haja interação cognitiva entre os novos conhecimentos e conhecimentos prévios especificamente relevantes, existentes na estrutura cognitiva do ser que aprende, e também em uma avaliação formativa e recursiva conforme sinaliza Moreira (2011).

Voltando para a aprendizagem ativa, em que o estudante é o protagonista e o professor um mediador, que leva ao aluno a ser mais participante de fato. Esse tipo de aprendizagem envolve falar e ouvir, ler, refletir e escrever recursivamente. Para isso podem ser propostas atividades individuais, em pares, em grupos ou projetos colaborativos a partir de perguntas, resolução de problemas, estudo dirigido, demonstrações, simulações, ensino com projetos e/ou com pesquisas, etc..

Durante meu estudo encontrei algumas sugestões de atividades e estratégias para trabalhar com os estudantes, de forma ativa, propostos por Richard Felder e Rebecca Brent (2009) como por exemplo: Colocar o problema e solicitar aos alunos que trabalhem individualmente por um curto período de tempo; depois, fazê-los formar pares, reconciliar e melhorar suas soluções; e, finalmente, convidar vários indivíduos ou 
pares para compartilharem suas respostas. Outras sugestões apresentadas por esses autores são: Resolução de problemas em voz alta. Evitar fazer exercícios por muito tempo; Solicitar voluntários para responder após cada atividade; Se alguns dos alunos não gostarem de serem chamados para trabalhar em sala de aula, explicar que se trata da aprendizagem ativa e que os alunos aprendem muito mais fazendo coisas e obtendo feedback do que assistindo e ouvindo alguém dizendo o que deveriam saber.

Também é importante levar em conta o conhecimento prévio do estudante, é a variável que mais influencia a aprendizagem; Estimular os alunos a perguntar, a buscar conhecimento ao invés de estimulá-los a saber respostas muitas vezes sem significado; Utilizar distintos materiais educativos (vídeos, histórias, músicas, jogos, teatro, paródias, etc.) e oferecer explicações aceitas no contexto da matéria ensinada, segundo diferentes perspectivas de distintos autores; Incentivar os alunos a serem detectores de erros, a buscarem outras explicações, ou seja, a aproveitar o erro como fator de aprendizagem, pois o conhecimento científico, por exemplo, progride corrigindo teorias erradas; Mostrar que o conhecimento humano é incerto, que depende das perguntas feitas (instrumentos de percepção), das definições e metáforas utilizadas (instrumentos para pensar); Ajudar os alunos a livrarem-se dos obstáculos epistemológicos e incentivá-los a desaprender (MOREIRA, 2005; 2011).

Lembre-se que podemos porporcionar estratégias instrucionais que levem o estudante a falar mais, ou seja, a externalizar para o professor os significados que está captando. Nesse aspecto, devemos abandonar a narrativa e proporcionar diálogo, interação social, intercâmbio e negociação de significados entre professor e aluno, entre os próprios alunos; promover situações que os alunos possam resolver colaborativamente, em pequenos grupos para que discutam, discordem, busquem consensos, contribuindo para a captação de significados, para que sintam que o foco do ensino é a sua aprendizagem. O resultado dessas atividades colaborativas deve ser apresentado ao grande grupo para submeterem-se à crítica dos demais colegas, pois a crítica, a argumentação e a autocrítica são importantes no processo de ensino e de aprendizagem (FELDER e BRENT, 2009; MOREIRA, 2005; 2011; ZWICKER, 2017).

Diante do que foi escrito anteriormente, percebemos que uma concepção mais adequada de aprendizagem envolve o trabalho do professor em estimular o estudante a ser protagonista do seu processo de desenvolvimento, pesquisando, investigando, refletindo, discutindo, articulando e gerindo seus próprios conhecimentos. Nesse 
aspecto, sugerir atividades que possibilitem momentos de interação tanto com o conteúdo a ser estudado quanto com os colegas e referenciais teóricos favorecem a aprendizagem ativa.

Neste contexto, o processo formativo Cirandar, proporciona a seus participantes diversos aspectos da aprendizagem ativa, ao propor a escrita sobre suas própria experiência relacionada a sala de aula por meio de cartas, são vistas como um meio mais acolhedor de escrever e de escolher uma temática de interesse para estudo permitindo pensar sobre o que se sabe a respeito desta. Ao enviar a carta para ser lida por outro(a) cirandeiro(a), esta se torna um meio de comunicar e também de escuta sobre o que se sabe, de ampliar sua perspectiva em relação ao tema estudado, a partir das indicações de referenciais teóricos e dos questionamentos realizados pelo par de leitura. Assim possibilitando a interação entre os participantes e a recursividade da escrita, tornando-se um modo de refletir e repensar a respeito da experiência narrada.

O Cirandar, além de proporcionar a experiência de uma aprendizagem ativa, em que os professores se tornaram protagonistas de seu estudo, também trata-se de um processo de formação de professores acadêmico-profissional (DINIZ-PEREIRA, 2008). Este permitiu entender que ser professor é ser mediador e também produtor de conhecimento, mas que depende da seriedade, da responsabilidade, do preparo científico, da reflexibilidade, da criatividade e mais do que nunca, exige preparo físico, emocional e afetivo além de um posicionamento político e ético conforme defendem Mello e Salomão de Freitas (2019). Para as autoras, estas características são desenvolvidas "na participação dos(as) professores(as) em processos de formação permanente, constituído por um coletivo integrado por profissionais com diferentes experiências" (p. 2014), como este que ocorre no Cirandar.

Relacionando a aprendizagem ativa proporcionada pelo Cirandar, em que cada participante pesquisou, refletiu, escreveu e interagiu com outro cirandeiro ou cirandeira, apresentamos algumas das aprendizagens relatadas pelo nosso grupo. De acordo com os participantes, as atividades de escrita do Cirandar nos instigaram a sair da bolha, olhar a nossa volta e conseguir ver lados positivos e também negativos que essa situação pandêmica nos trouxe.

Entre os pontos negativos, a sensação de angústia que todos partilhávamos, devido às incertezas, mas também devido à desigualdade social, evidenciada pelas condições socioeconômicas, emocionais e familiares que determinaram o envolvimento 
dos alunos e de suas famílias com as propostas enviadas pelos professores e também o trancamento de matrículas na universidade.

Nos aspectos positivos, o relato do licenciando bolsista do programa de Residência Pedagógica ao investigar sua própria sala de aula, contando sobre sua pesquisa via formulário para ter um feedback dos alunos que o fez repensar a organização das aulas, as metodologias utilizadas. Também promoveu reflexão sobre como estava exercendo seu papel de professor, de como está dando um retorno à seus alunos mesmo estando distante.

No relato de outra professora, sobre escrever as cartas sobre o seu fazer pedagógico e o ser professora, ela se surpreendeu ao perceber o quanto fluíram a escrita e a reflexão através desta proposta livre e provocadora do Cirandar. Segundo esta professora, este modo de formação potencializa o pensamento sobre as vivências e práticas com os estudantes por meio do compartilhamento em Roda, ressaltando a (re)significação de sua experiência a partir das indagações de sua dupla de leitura. Para evidenciar essa percepção, ela partilhou conosco uma mandala azul mostrada na Figura 1, para deixar registrado que o coletivo, o Cirandar, assim como os círculos, fazem com que enriqueçamos diante da percepção das multiplicidades e das diferenças.

\section{Figura 1 - Mandala Azul}

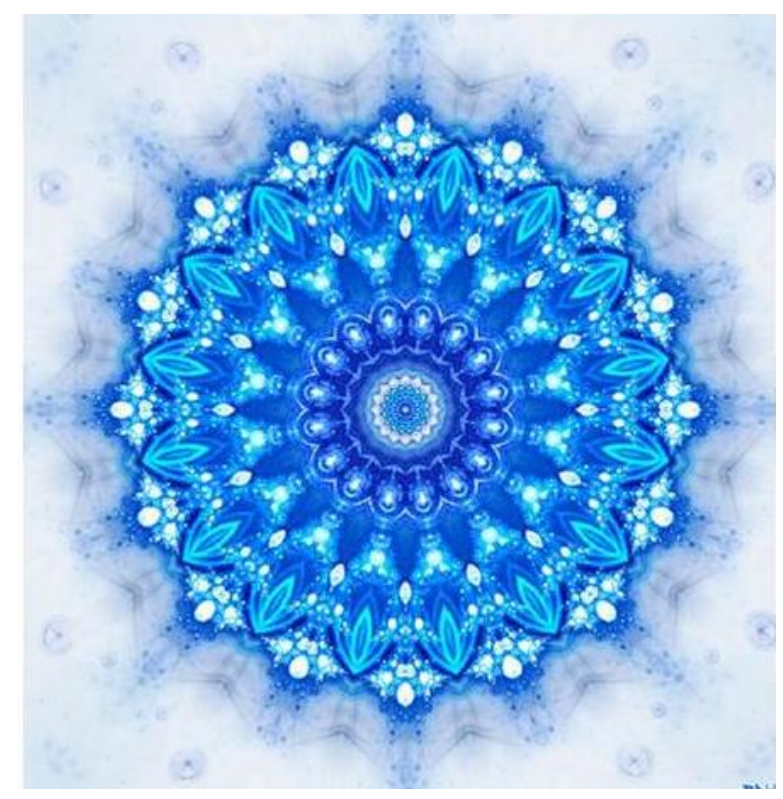

Fonte: https://br.pinterest.com/pin/188025353167795812/(2021)

A partir da escrita das cartas, percebemos o quanto se tem pouco tempo para ler e refletir sobre algo além das atividades que envolvem o trabalho vinculado a uma 
componente específica ou de gestão. Também identificamos a saudade que temos da presença física dos estudantes na sala de aula.

Para os professores deste grupo, este período provocado pela pandemia em que tivemos que trabalhar de modo remoto, sem previsão de retomar a normalidade, nos fez repensar a prática pedagógica, diante de muitos desafios e obstáculos que causaram em muitos professores sentimentos de medo e de frustração. Também trouxe a necessidade de mudança, de um novo olhar para o planejamento de aulas, do processo de ensino e de aprendizagem e sobre a inserção da tecnologia como algo a agregar na sala de aula.

Este momento também provocou questionamentos, alguns levantados pelos pares de leitura, como: Qual o sentido de ser professor nos dias de hoje? O sentido de ser professor quando as condições de trabalho muitas vezes revelam-se tão precárias? Qual o sentido de ser professor quando competimos com tantas fontes de informações como celulares, notebooks, tablets, entre tantos? Ainda não temos as respostas a essas perguntas, mas elas nos instigam a seguir nos questionando sobre a profissão docente.

Diante do exposto, o processo formativo Cirandar realizado nesta edição totalmente à distância, foi intenso na partilha de experiências e sentimentos aqui na região de Bagé, em que os participantes já sinalizaram sobre temas de interesse para estudo na próxima edição desse projeto. Entre eles, as dificuldades que os estudantes enfrentaram em 2020 tanto dos que tiveram acesso quanto dos que não têm acesso as tecnologias digitais; o mundo pós-vacina.

E assim, finalizo essa carta com muitas incertezas, agora já com perdas de pessoas próximas, mas com a certeza de que não estamos sozinhos e com a esperança da vacina para todos e com as imagens de frutíferas silvestres (pitangueira e cerejeira) no bairro onde moro. Elas estão apresentadas na Figura 2 e foram fotografadas no mês de novembro de 2020. Estas me trouxeram as memórias da infância, quando se vivia um dia de cada vez.

\section{Figura 2 - Pitangueira e Cerejeira}




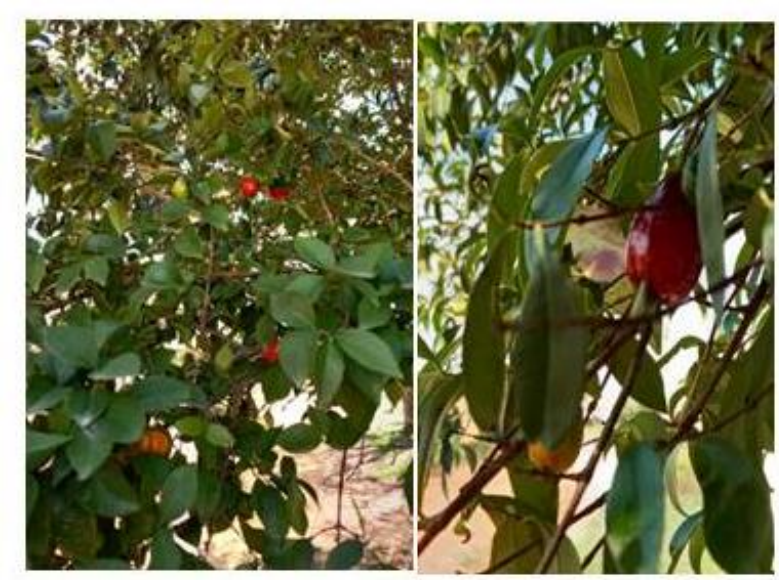

Fonte: Fotografia registrada pela autora (2020)

Que tenhamos dias melhores e até qualquer dia!

Abraços da Márcia Firme

\section{REFERÊNCIAS}

BRANDÃO, Carlos Rodrigues. Comunidades Aprendentes. In: FERRARO JÚNIOR, Luiz Antonio. Encontros e Caminhos: Formação de Educadoras(es) Ambientais e Coletivos Educadores. Brasília: Ministério do Meio Ambiente, 2005.

DINIZ-PEREIRA, Júlio Emílio. A formação acadêmico-profissional: compartilhando responsabilidades entre universidades e escolas. In: XIV ENDIPE. Porto Alegre, RS, 2008.

FELDER, Richard M.; BRENT, Rebecca. Active learning: An introduction. January 2009. Disponível em: https://www.researchgate.net/publication/242102584. Acesso em: 25 de mar. 2021.

IZQUIERDO, I. Memória. 2 ed. Porto Alegre: Artmed, 2011.

MELLO, Elena Maria Billig; SALOMÃO DE FREITAS, Diana Paula. Formação acadêmico- profissional de professores(as). Formação Docente, Belo Horizonte, v. 11, n.20, jan./abr. 2019. Disponível em: https://revformacaodocente.com.br/index.php/ rbpfp/article/view/215/199. Acesso em: 23 mar. 2021.

MOREIRA, M.A. (2005). Aprendizagem significativa crítica. Porto Alegre: Instituto de Física, UFRGS. Disponível em: http://moreira.if.ufrgs.br/oqueeafinal.pdf . 
Acesso: 20 mar. 2021.

MOREIRA, Marco Antonio. Abandono da narrativa, ensino centrado no aluno e Aprender a aprender criticamente. Revista Eletrônica do Mestrado Profissional em Ensino de Ciências da Saúde e do Ambiente. v.4 n1 p.2-17, Abril 2011. Disponível em: http://moreira.if.ufrgs.br/oqueeafinal.pdf. Acesso: 20 mar. 2021.

MORIN, Edgar. Um festival de incerteza. Sem Fronteiras. 1 de Junho de 2020. Disponível em: https://www.insurgencia.org/blog/edgar-morin-um-festival-de-incerteza Acesso: 18 mar. 2021.

ZWICKER, Melanie Retz Godoy dos Santos. A aprendizagem ativa e o cérebro: contribuições da neurociência para uma nova forma de educar. In: SANTOS, Célia Maria Retz Godoy dos; FERRARI, Maria Aparecida (org.) Aprendizagem ativa: contextos e experiências em comunicação. Bauru: Universidade Estadual Paulista, Faculdade de Arquitetura, Artes e Comunicação, 2017. p.49-74. Disponível em: www.faac.unesp.br/\#!/publicacoes/. Acesso: 25 mar. 2021.

Recebido em: 28 de maio de 2021.

Aceito em: 08 de junho de 2021. 